\title{
Development and validation of a clinical prediction score for poor postoperative pain control following elective spine surgery
}

\author{
Presented at the 2020 AANS/CNS Joint Section on Disorders of the Spine and Peripheral Nerves \\ Michael M. H. Yang, MD, MSc, MBiotech,,2 Jay Riva-Cambrin, MD, MSc, ${ }^{1,2}$ \\ Jonathan Cunningham, MSc, ${ }^{1}$ Nathalie Jetté, MD, MSc, ${ }^{1-3}$ Tolulope T. Sajobi, PhD, ${ }^{2}$ \\ Alex Soroceanu, MD, MPH, ${ }^{4}$ Peter Lewkonia, MD, MSc, ${ }^{4}$ W. Bradley Jacobs, MD, ${ }^{1}$ and \\ Steven Casha, MD, $\mathrm{PhD}^{1,5}$
}

Departments of ${ }^{1}$ Clinical Neurosciences, Section of Neurosurgery, ${ }^{2}$ Community Health Sciences, and ${ }^{4}$ Surgery, Section of Orthopaedic Surgery, and ${ }^{5}$ Hotchkiss Brain Institute, University of Calgary, Alberta, Canada; and ${ }^{3}$ Department of Neurology, Icahn School of Medicine at Mount Sinai, New York, New York

OBJECTIVE Thirty percent to sixty-four percent of patients experience poorly controlled pain following spine surgery, leading to patient dissatisfaction and poor outcomes. Identification of at-risk patients before surgery could facilitate patient education and personalized clinical care pathways to improve postoperative pain management. Accordingly, the aim of this study was to develop and internally validate a prediction score for poorly controlled postoperative pain in patients undergoing elective spine surgery.

METHODS A retrospective cohort study was performed in adult patients ( $\geq 18$ years old) consecutively enrolled in the Canadian Spine Outcomes and Research Network registry. All patients underwent elective cervical or thoracolumbar spine surgery and were admitted to the hospital. Poorly controlled postoperative pain was defined as a mean numeric rating scale score for pain at rest of $>4$ during the first 24 hours after surgery. Univariable analysis followed by multivariable logistic regression on 25 candidate variables, selected through a systematic review and expert consensus, was used to develop a prediction model using a random $70 \%$ sample of the data. The model was transformed into an eight-tier risk-based score that was further simplified into the three-tier Calgary Postoperative Pain After Spine Surgery (CAPPS) score to maximize clinical utility. The CAPPS score was validated using the remaining $30 \%$ of the data.

RESULTS Overall, $57 \%$ of 1300 spine surgery patients experienced poorly controlled pain during the first 24 hours after surgery. Seven significant variables associated with poor pain control were incorporated into a prediction model: younger age, female sex, preoperative daily use of opioid medication, higher preoperative neck or back pain intensity, higher Patient Health Questionnaire-9 depression score, surgery involving $\geq 3$ motion segments, and fusion surgery. Notably, minimally invasive surgery, body mass index, and revision surgery were not associated with poorly controlled pain. The model was discriminative (C-statistic $0.74,95 \% \mathrm{Cl} 0.71-0.77$ ) and calibrated (Hosmer-Lemeshow goodness-of-fit, $p=$ 0.99 ) at predicting the outcome. Low-, high-, and extreme-risk groups stratified using the CAPPS score had $32 \%, 63 \%$, and $85 \%$ predicted probability of experiencing poorly controlled pain, respectively, which was mirrored closely by the observed incidence of $37 \%, 62 \%$, and $81 \%$ in the validation cohort.

CONCLUSIONS Inadequate pain control is common after spine surgery. The internally validated CAPPS score based on 7 easily acquired variables accurately predicted the probability of experiencing poorly controlled pain after spine surgery.

https://thejns.org/doi/abs/10.3171/2020.5.SPINE20347

KEYWORDS postoperative pain; spine surgery; clinical prediction score; pain measurement

ABBREVIATIONS aOR = adjusted odds ratio; CAPPS = Calgary Postoperative Pain After Spine Surgery; CSORN = Canadian Spine Outcomes and Research Network; NRS = numeric rating scale; PHQ-9 = Patient Health Questionnaire-9; SSLR = stratum-specific likelihood ratio.

ACCOMPANYING EDITORIAL See pp 1-2. DOI: 10.3171/2020.6.SPINE20803.

SUBMITTED March 23, 2020. ACCEPTED May 6, 2020.

INCLUDE WHEN CITING Published online September 15, 2020; DOI: 10.3171/2020.5.SPINE20347. 
$\mathrm{T}$ HE increasing age of our population together with improved access to diagnostic and imaging technologies has led to an increase in the number of spine operations being performed in North America., ${ }^{1,2}$ The number of cervical spine procedures performed in the US between 1990 and 2000 increased 2-fold. ${ }^{1}$ Similarly, Medicare spending for inpatient thoracolumbar surgery doubled over a 10 -year period to $\$ 1$ billion (USD). ${ }^{2}$

Poor pain control after surgery may lead to patient dissatisfaction, delayed recovery, postoperative opioid dependence, and prolonged hospital stay. ${ }^{3}$ In addition, poor pain control has been associated with complications such as the development of chronic pain syndromes, thromboembolic diseases, and delirium in the elderly. ${ }^{3,4}$ It is estimated that the economic burden of treating chronic pain that develops following acute pain in a 30-year-old individual over a lifetime is as much as $\$ 1$ million (USD). ${ }^{5}$ Thus, prevention and effective relief of acute pain may improve clinical outcomes, save healthcare resources, and improve quality of life.

Several efforts have been made to improve postoperative pain management through the implementation of practice guidelines, use of preemptive analgesia, and increased availability of acute pain service teams. ${ }^{6,7}$ Despite these efforts, $30 \%-64 \%$ of patients continue to report poorly controlled pain after spine surgery. ${ }^{8}$

This undesirable situation may in part be due to a lack of insight into the variables associated with the experience of poor pain control after spine surgery. ${ }^{9}$ The identification of at-risk patients before surgery may allow for preventative and personalized treatment strategies in the preoperative and perioperative settings to improve pain. The goals of this study were to 1) establish the predictors of poorly controlled postoperative pain after elective spine surgery and 2) develop and internally validate a clinical prediction score to aid clinicians in risk-stratifying patients in the preoperative setting.

\section{Methods}

This study was conducted and reported in accordance with the Transparent Reporting of a Multivariable Prediction Model for Individual Prognosis or Diagnosis (TRIPOD) statement. ${ }^{10}$ Ethics approval for this study was provided by the University of Calgary's Conjoint Health Research Ethics Board, and all patients provided informed consent.

\section{Study Population}

Patients were consecutively enrolled through the hospital-based prospective Canadian Spine Outcomes and Research Network (CSORN) spine registry between August 28, 2014, and October 4, 2017, at the Foothills Medical Centre in Calgary, Alberta, Canada. ${ }^{11}$ This tertiary care center performs the vast majority of spine surgeries in southern Alberta with a catchment area of more than 2 million people. All candidate prognostic variables were collected prospectively through the CSORN registry, which undertook quarterly audits to ensure data accuracy.

\section{Entry Criteria}

Adults ( $\geq 18$ years) who underwent elective cervical or thoracolumbar spine surgery and required hospital admission for at least 24 hours were included. Exclusion criteria included receiving intraoperative intrathecal or postoperative epidural analgesia (previously shown to provide significant improvement in postoperative pain intensity compared with placebo ${ }^{12,13}$ ), admission to the intensive care unit, spine surgery for acute trauma, concurrent cervical and thoracolumbar surgeries, more than one surgery performed on the same day, and fewer than 2 postoperative numeric rating scale (NRS) pain evaluations recorded in the first 24 hours. Preemptive analgesia and intraoperative local anesthetic use were not standardized.

\section{Outcome}

The primary outcome was poor postoperative pain control, defined as a mean NRS score for pain at rest $>4$ in the first 24 hours after surgery (postoperative day 1). ${ }^{14}$ The NRS records pain intensity on an 11-point scale (where 0 indicates no pain and 10 indicates worst pain possible) and has been shown to have intrarater, interrater, and predictive validity and reliability. ${ }^{14,15}$ An NRS score of 4 has previously been established as the threshold for tolerable postoperative pain. ${ }^{14}$ Conversely, a postoperative NRS score > 4 has been associated with pain requiring analgesic interventions and negative pain-related adverse events such as decreased mobility, sleep, and mood. ${ }^{14}$ In this study, the NRS score for pain was recorded by clinical care nurses, without knowledge of the research objectives, as part of usual patient care after surgery. Patients were asked while recumbent to verbally rate their pain by selecting an integer on a scale of 0-10 as defined above. That outcome was collected retrospectively from patient records. The frequency of pain assessments was personalized to the patient. At a minimum, assessments occurred before administration of postoperative analgesic medications (opioid and nonopioid medications) and every 6 hours, according to our institutional policy. The assessments every 6 hours might have been deferred for asleep patients and for medically stable patients when they were away from the clinical unit (e.g., while undergoing postoperative radiographs). Generally, assessments were performed more frequently when pain was poorly controlled. To evaluate the accuracy of the abstraction process, outcome abstraction was performed in duplicate for 100 random patients, and major errors, defined as outcomes that were classified differently (mean NRS score $\leq 4$ vs $>4$ ), were determined and compared.

\section{Variable Selection}

Twenty-five preoperative prognostic variables were selected from 85 potential variables in the CSORN registry (eTable 1). ${ }^{11}$ To facilitate variable selection, a systematic review and meta-analysis was performed and previously published that identified 9 significant preoperative predictors of poorly controlled postoperative pain across all surgical disciplines. ${ }^{9}$ All 9 variables were included, with the exception of preoperative anxiety, which was not captured in the registry. Seventeen additional variables that would be known in the preoperative setting were also included after consensus decision by three neurosurgeons, one neurologist, and one biostatistician. Variable selection 
was based on the following criteria: potential relevance in predicting postoperative pain, likelihood of additional substantial prognostic information beyond what other variables provide, discrete and readily interpretable, and feasible to collect by any spine center. ${ }^{16,17}$

\section{Sample Size}

Based on simulations of logistic regression analyses, having at least 10 outcome events for each degree of freedom avoids biased regression coefficients, inaccurate variance estimates, and paradoxical associations. ${ }^{18}$ Using a conservative estimated incidence of poor postoperative pain of $30 \%,{ }^{8}$ we determined that a minimum sample size of 834 in the model development cohort was required to adequately evaluate 25 degrees of freedom (e.g., 25 continuous or dichotomous variables).

\section{Statistical Analysis}

The overall sample $(n=1300)$ was randomly divided (without replacement) into a model development cohort $(70 \%, \mathrm{n}=910)$ and a model internal validation cohort $(30 \%, \mathrm{n}=390)$ using a deterministic random bit generator.

\section{Identification of Predictors for Poor Postoperative Pain Control}

Multicollinearity among variables was examined by and indicated by a variance inflation factor $>5 .{ }^{19}$ If collinear variables were detected, one of the variables was removed after expert consensus. The chi-square test and Student t-test were used to compare categorical and continuous variables to the primary outcome, respectively. Variables exhibiting a $p$ value $\leq 0.10$ on univariable analyses were further evaluated by multivariable logistic regression. A Markov chain Monte Carlo multiple imputation model with 20 imputations was used to manage missing data (eTable 2). The final model was derived using a backward variable selection method until all predictors exhibited a $\mathrm{p}$ value $\leq 0.05$. Surgery site (cervical or thoracolumbar) was forced into the model to adjust for the effect of location of surgery on pain control. Apparent model performance was measured by the C-statistic for discrimination and the Hosmer-Lemeshow goodness-of-fit test using 10 groups for calibration.

\section{Clinical Prediction Score Development}

To facilitate the development of a clinical prediction score, all significant continuous variables in the final model were dichotomized (a threshold was chosen based on clinical experience and past literature) (eTable 3), and the multivariable analysis was repeated. The adjusted odds ratio (aOR) for each significant variable was rounded to the nearest integer to establish each predictor's numeric score in the clinical prediction score. ${ }^{20}$ Posttest odds of poor pain control were calculated for each tier of the score and converted to the posttest predicted probability (Bayes' theorem). ${ }^{21}$ Adjacent cells with small sample sizes were grouped until all cells had $\geq 5$ patients, and the stratumspecific likelihood ratios (SSLRs) were recalculated, resulting in an eight-tier Calgary Postoperative Pain After Spine Surgery (CAPPS) prediction score. As an alterna- tive, for convenience and improved clinical penetrance, a three-tier CAPPS score was also developed: low risk (scores 0-4; SSLRs $\leq 1$ ), high risk (scores 5-8; SSLRs > 1 and $\leq 4$ ), and extreme risk (scores 9-13; SSLRs $>4$ ). ${ }^{22}$

\section{Clinical Prediction Score Validation}

The eight- and three-tier CAPPS scores were applied to all patients in the validation cohort, and the predicted probability for poorly controlled pain was calculated. For calibration, the predicted probabilities were graphically compared with the observed incidence in the validation cohort for each tier. ${ }^{23}$ Discrimination of the three-tier CAPPS was evaluated using percentage misclassification with the low-risk group as the reference group. ${ }^{24}$

The alpha level was set to 0.05 for significance. All statistical analyses were performed using Stata (version 15.1, StataCorp).

\section{Results}

Of 1740 patients, 1300 met the entry criteria (Fig. 1). There was no patient attrition during outcome collection. The mean age was 59.5 years, and $48.5 \%$ of patients were female (Table 1). The most common principal pathology and chief complaint were spinal stenosis $(39.2 \%)$ and radiculopathy $(42.2 \%)$, respectively. Sixty-one percent of patients underwent fusion. The mean number of motion segments (any part of 2 adjacent articulating vertebrae) operated on was 1.9. Preoperative daily nonopioid and opioid medications were consumed by $48.5 \%$ and $32.4 \%$ of patients, respectively. Of the patients taking daily opioids, $96.4 \%$ had been doing so for $>3$ months. The mean number of NRS pain evaluations in the first 24 hours after surgery was 9.2 (SD 3.2). Poor postoperative pain control at rest (NRS score $>4$ ) on postoperative day 1 was observed in $56.7 \%$ (95\% CI 54.1\%-59.4\%, $\mathrm{n}=738$ ) of patients. There was no difference in the incidence of poorly controlled pain between the cervical and thoracolumbar groups $(59.8 \%$ vs $55.7 \%, \mathrm{p}=0.20)$. Patients with poor pain control consumed more oral morphine equivalent doses than those who had good pain control (188.8 mg vs 66.1 $\mathrm{mg}, \mathrm{p}<0.001)$ in the first 24 hours after surgery. All variables were comparable in the model development and validation cohorts (eTable 4). There was 1 major error in abstracting the primary outcome in 100 random patients, suggesting a $1.0 \%(95 \%$ CI $0.58 \%-1.71 \%)$ error rate.

\section{Predictor Identification and Model Development}

Nine hundred ten patients were randomly selected for the model development cohort. On univariable analysis, 17 variables were found to be significantly associated with poor pain control (NRS $>4$ ) (Table 2). Notably, body mass index, surgical approach (anterior, posterior, or anteriorposterior), revision surgery, grade 3 osteotomy or higher, ${ }^{25}$ and minimally invasive surgery were not significantly associated with poor pain control.

In the subsequent multivariable model, 7 variables were found to be independently predictive of poor postoperative pain control: younger age in years $(\mathrm{aOR} 1.02,95 \%$ CI 1.01-1.03; $\mathrm{p}=0.001)$, female sex (aOR 1.64, 95\% CI $1.22-2.19 ; \mathrm{p}=0.001$ ), preoperative daily opioid medica- 


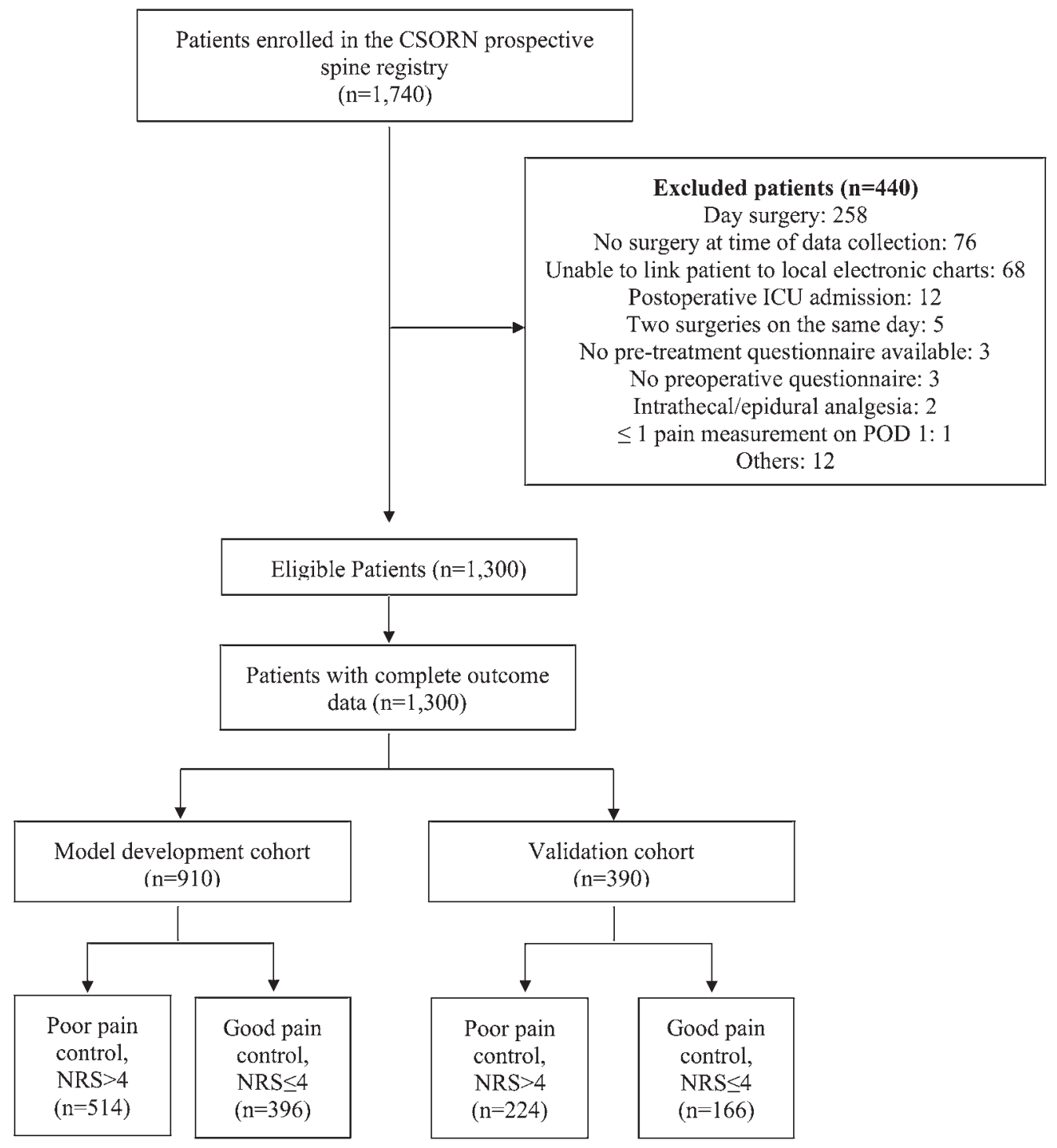

FIG. 1. Participant flow diagram. $P O D=$ postoperative day.

tion use (aOR 2.61, 95\% CI 1.57-2.89; $\mathrm{p}<0.001$ ), higher preoperative neck or back pain measured by NRS (aOR 1.20, 95\% CI 1.06-1.20; p < 0.001), higher Patient Health Questionnaire-9 (PHQ-9) depression score (aOR 1.03, 95\% CI $1.001-1.06 ; \mathrm{p}=0.039$ ), surgery on 3 or more motion segments (aOR 2.17, 95\% CI 1.48-3.19; $\mathrm{p}<0.001$ ), and fusion surgery (aOR 2.13, 95\% CI 1.57-2.89; p < 0.001) (eTable 5).

This model demonstrated good calibration (HosmerLemeshow $\chi^{2}=1.59, p=0.99$ ), suggesting that the predicted probability of poor pain control was not significantly different from the observed probability. The C-statistic was 0.74 (95\% CI 0.71-0.77), indicating that the model adequately discriminated between patients with good and poor pain control (eFig. 1A).

\section{Clinical Prediction Score}

To facilitate clinical application, a clinical prediction score with 14 possible scores (0-13) was created after dichotomizing continuous variables (Table 3 ). No erosion of discrimination (C-statistic $0.73,95 \%$ CI $0.70-0.77$ ) or calibration (Hosmer-Lemeshow $\chi^{2}=6.70, p=0.46$ ) was seen after this transformation. That prediction score was further collapsed into an eight-tier CAPPS score after adjacent cells with small sample sizes were combined. This eight-tier CAPPS score retained discrimination (Cstatistic $0.73,95 \%$ CI $0.69-0.76$ ) and calibration (HosmerLemeshow $\left.\chi^{2}=11.05, p=0.09\right)$ (eFig. 1B).

Bayesian statistics were then applied to develop the SSLRs and the resultant predicted posttest probabilities for each of the eight tiers (Table 4). The SSLRs progressed from a low of 0.25 for scores $0-2$ to 4.40 for patients with scores $\geq 9$. Using a pretest probability of $56.5 \%$ (the incidence of poor pain control in the model development cohort), the posttest predicted probability of poor pain control progressed from $24.2 \%$ for scores $0-2$ to $85.1 \%$ for patients with scores $\geq 9$. Furthermore, when the CAPPS 
TABLE 1. Baseline patient characteristics $(n=1300)$

\begin{tabular}{|c|c|c|}
\hline Characteristic & Value & $\begin{array}{c}\text { No. of } \\
\text { Missing } \\
\text { Values (\%) }\end{array}$ \\
\hline Age in yrs, mean \pm SD & $59.5 \pm 13.6$ & $0(0)$ \\
\hline Female sex, $\mathrm{n}(\%)$ & $630(48.5)$ & $0(0)$ \\
\hline Principal pathology, n (\%) & & $0(0)$ \\
\hline Disc herniation & $172(13.2)$ & \\
\hline Degenerative disc disease & $166(12.8)$ & \\
\hline Spinal stenosis & $509(39.2)$ & \\
\hline Spondylolisthesis & $306(23.5)$ & \\
\hline Deformity & $71(5.5)$ & \\
\hline Tumor & $23(1.8)$ & \\
\hline Other & $53(4.1)$ & \\
\hline Chief complaint, $n(\%)$ & & $0(0)$ \\
\hline Back pain & $236(18.2)$ & \\
\hline Neck pain & $17(1.3)$ & \\
\hline Radiculopathy & $548(42.2)$ & \\
\hline Myelopathy & $180(13.8)$ & \\
\hline Neurogenic claudication & $304(23.4)$ & \\
\hline Other & $15(1.2)$ & \\
\hline $\begin{array}{l}\text { No. of NRS pain evaluations on postop } \\
\text { day } 1 \text {, mean } \pm S D\end{array}$ & $9.2 \pm 3.2$ & $0(0)$ \\
\hline $\begin{array}{l}\text { Patients w/ NRS score }>4 \text { for pain on } \\
\text { postop day } 1, \%(95 \% \mathrm{Cl})\end{array}$ & $56.7(54.1-59.4)$ & $0(0)$ \\
\hline $\begin{array}{l}\text { Oral MED on postop day } 1 \mathrm{in} \mathrm{mg} \\
\text { mean } \pm \mathrm{SD}\end{array}$ & $135.4 \pm 175.1$ & $0(0)$ \\
\hline $\mathrm{BMI}$ in $\mathrm{kg} / \mathrm{m}^{2}$, mean $\pm \mathrm{SD}$ & $29.2 \pm 5.6$ & $0(0)$ \\
\hline Any nicotine products, n (\%) & $255(19.6)$ & $0(0)$ \\
\hline High school education or less, $n(\%)$ & $503(40.0)$ & $44(3.4)$ \\
\hline Single, $\mathrm{n}(\%)$ & $340(26.4)$ & $11(0.8)$ \\
\hline History of spine surgery, $n(\%)$ & $330(25.4)$ & $0(0)$ \\
\hline ASA physical status, $n(\%)$ & & $0(0)$ \\
\hline Class I & $256(19.7)$ & \\
\hline Class II & $777(59.8)$ & \\
\hline Class III & $263(20.2)$ & \\
\hline Class IV & $4(0.3)$ & \\
\hline Sleep difficulty, n (\%) & $985(77.3)$ & $25(1.9)$ \\
\hline Daily nonopioid medication, $\mathrm{n}(\%)$ & $612(48.5)$ & $38(2.9)$ \\
\hline Daily opioid medication, n (\%) & $396(32.4)$ & $78(6.0)$ \\
\hline Daily antidepressant medication, $\mathrm{n}(\%)$ & $291(24.4)$ & $106(8.2)$ \\
\hline Daily neuroleptic medication, $\mathrm{n}(\%)$ & $417(34.5)$ & $93(7.2)$ \\
\hline Chronic pain, n (\%) & $981(79.4)$ & $65(5.0)$ \\
\hline $\begin{array}{l}\text { Preop neck or back pain on NRS, } \\
\text { mean } \pm \text { SD }\end{array}$ & $6.7 \pm 2.4$ & $17(1.3)$ \\
\hline Depression on $\mathrm{PHQ}-9$, mean $\pm \mathrm{SD}$ & $9.6 \pm 6.3$ & $88(6.8)$ \\
\hline $\begin{array}{l}\text { Severe preop disability on NDI or ODI, } \\
n(\%)^{*}\end{array}$ & $691(56.5)$ & $78(6.0)$ \\
\hline Surgical approach, n (\%) & & $0(0)$ \\
\hline Any anterior & $311(23.9)$ & \\
\hline Any posterior & $930(71.5)$ & \\
\hline Any anterior \& posterior & $59(4.5)$ & \\
\hline
\end{tabular}

CONTINUED IN NEXT COLUMN »
» CONTINUED FROM PREVIOUS COLUMN

TABLE 1. Baseline patient characteristics $(n=1300)$

\begin{tabular}{llc}
\hline \multicolumn{1}{c}{ Characteristic } & Value & $\begin{array}{c}\text { No. of } \\
\text { Missing } \\
\text { Values (\%) }\end{array}$ \\
\hline No. of motion segments treated, $\mathrm{n}(\%)$ & $0(0)$ \\
\hline 1 & $650(50)$ & \\
\hline 2 & $379(29.2)$ & \\
\hline$\geq 3$ & $271(20.9)$ & $0(0)$ \\
\hline Fusion surgery, $\mathrm{n}(\%)$ & $793(61.0)$ & $0(0)$ \\
\hline Minimally invasive surgery, $\mathrm{n}(\%)$ & $318(24.5)$ & $0(0)$ \\
\hline Revision surgery, $\mathrm{n}(\%)$ & $189(14.5)$ & $0(0)$ \\
\hline Grade $\geq 3$ osteotomy, ${ }^{25} \mathrm{n}(\%) \dagger$ & $55(4.2)$ &
\end{tabular}

$\mathrm{ASA}=$ American Society of Anesthesiologists; $\mathrm{MED}=$ morphine equivalent dose; $\mathrm{NDI}=$ Neck Disability Index; ODI = Oswestry Disability Index.

${ }^{*}$ Neck Disability Index $\geq 50$ and Oswestry Disability Index $>40$.

$\dagger$ At least pedicle or partial body resection.

score was streamlined into a three-tier score for maximal clinical convenience, there was a similar stepwise increase in the predicted probability of poor pain control: $32.0 \%$ for low-risk (scores 0-4), 63.0\% for high-risk (scores 5-8), and $85.1 \%$ for extreme-risk (scores 9-13) groups.

\section{Validation of Prediction Score}

The validation cohort included 390 patients randomly selected from the original sample (eTable 4). The CAPPS score's performance was assessed in this independent validation cohort. The predicted probabilities derived from both the eight-tier and three-tier CAPPS score closely matched the incidence of poor pain control observed in the validation cohort (Fig. 2). When each patient within the validation cohort was risk-stratified using the threetier CAPPS score, the percentage misclassification between low and high risk was $38.0 \%$ (sensitivity: $74.8 \%$, 95\% CI 66.9\%-81.7\%; specificity: $47.7 \%$, 95\% CI 38.8\%$56.7 \%$ ). When stratified between low and extreme risk, the percentage misclassification was $29.9 \%$ (sensitivity: $60.0 \%, 95 \%$ CI $49.1 \%-70.2 \%$; specificity: $82.4 \%, 95 \%$ CI $71.8 \%-90.3 \%$ ), suggesting good predictive ability of the prediction score.

\section{Discussion}

As clinical practice moves toward personalized medicine, there is an increasing need for reliable predictive tools to help physicians make appropriate therapeutic decisions. In this study, preoperative factors that predict poorly controlled pain after elective spine surgery were identified and integrated into the internally validated CAPPS score.

Daily use of opioid medications preoperatively was the strongest predictive risk factor for developing poorly controlled pain, consistent with previous reports. ${ }^{26}$ Although opioid medications are effective in the treatment of acute pain, their long-term (>3 months) efficacy in sustaining pain relief, improving functional outcome, and safety in comparison with nonopioid medications has not been sub- 
TABLE 2. Univariable analyses of the model development cohort for 25 candidate variables $(n=910)$

\begin{tabular}{|c|c|c|c|c|}
\hline \multirow[b]{2}{*}{ Variable } & \multirow[b]{2}{*}{ Sample Size } & \multicolumn{2}{|c|}{ Pain Control* } & \multirow[b]{2}{*}{$p$ Value } \\
\hline & & Good $(n=396)$ & Poor $(n=514)$ & \\
\hline Age in yrs, mean $\pm S D$ & 910 & $61.9 \pm 13.7$ & $58.1 \pm 13.7$ & $<0.001$ \\
\hline Female sex, $\mathrm{n}(\%)$ & 910 & $158(39.9)$ & $284(55.3)$ & $<0.001$ \\
\hline Principal pathology, n (\%) & 910 & & & \\
\hline Disc herniation & & $53(13.4)$ & $71(13.8)$ & \multirow{7}{*}{0.003} \\
\hline Degenerative disc disease & & $38(9.6)$ & $73(14.2)$ & \\
\hline Spinal stenosis & & $181(45.7)$ & $179(34.8)$ & \\
\hline Spondylolisthesis & & $92(23.2)$ & $127(24.7)$ & \\
\hline Deformity & & $12(3.0)$ & $32(6.2)$ & \\
\hline Tumor & & $9(2.3)$ & $6(1.2)$ & \\
\hline Other & & $11(2.8)$ & $26(5.1)$ & \\
\hline Chief complaint, $\mathrm{n}(\%)$ & 910 & & & \\
\hline Back pain & & $48(12.1)$ & $113(22.0)$ & \multirow{6}{*}{0.001} \\
\hline Neck pain & & $2(0.5)$ & $8(1.6)$ & \\
\hline Radiculopathy & & $177(44.7)$ & $202(39.3)$ & \\
\hline Myelopathy & & $54(13.6)$ & $76(14.8)$ & \\
\hline Neurogenic claudication & & $112(28.3)$ & $109(21.2)$ & \\
\hline Other & & $3(0.8)$ & $6(1.2)$ & \\
\hline $\mathrm{BMl}$ in $\mathrm{kg} / \mathrm{m}^{2}$, mean $\pm \mathrm{SD}$ & 910 & $29.2 \pm 5.4$ & $29.3 \pm 5.9$ & 0.86 \\
\hline Any nicotine products, $\mathrm{n}(\%)$ & 910 & $62(15.7)$ & $112(21.8)$ & 0.02 \\
\hline High school education or less, $n$ (\%) & 877 & $143(37.4)$ & $209(42.2)$ & 0.15 \\
\hline Marital status: single, $\mathrm{n}(\%)$ & 900 & $89(22.7)$ & $141(27.8)$ & 0.085 \\
\hline History of spine surgery, $\mathrm{n}(\%)$ & 910 & $81(20.5)$ & $148(28.8)$ & 0.004 \\
\hline ASA physical status, $\mathrm{n}(\%)$ & 910 & & & \\
\hline Class I & & $74(18.7)$ & $106(20.6)$ & \multirow{4}{*}{0.14} \\
\hline Class II & & $253(63.9)$ & $292(56.8)$ & \\
\hline Class III & & $67(16.9)$ & $114(22.2)$ & \\
\hline Class IV & & $2(0.5)$ & $2(0.4)$ & \\
\hline Sleep difficulty, $\mathrm{n}(\%)$ & 892 & $267(69.7)$ & $418(82.1)$ & $<0.001$ \\
\hline Daily nonopioid medication, n (\%) & 885 & $159(41.4)$ & $260(51.9)$ & 0.002 \\
\hline Daily opioid medication, $\mathrm{n}(\%)$ & 861 & $69(18.4)$ & $208(42.9)$ & $<0.001$ \\
\hline Daily antidepressant medication, $n(\%)$ & 841 & $66(17.7)$ & $143(30.6)$ & $<0.001$ \\
\hline Daily neuroleptic medication, $\mathrm{n}(\%)$ & 854 & $111(29.4)$ & $184(38.7)$ & 0.005 \\
\hline Chronic pain, $\mathrm{n}(\%)$ & 865 & $265(71.2)$ & $423(79.5)$ & $<0.001$ \\
\hline Preop neck or back pain on NRS, mean \pm SD & 896 & $6.0 \pm 2.7)$ & $7.1 \pm 2.2$ & $<0.001$ \\
\hline Depression on PHQ-9, mean \pm SD & 849 & $8.0 \pm 5.7)$ & $10.7 \pm 6.4$ & $<0.001$ \\
\hline Severe preop disability on NDI or ODI, $n(\%) \dagger$ & 852 & $179(37.1)$ & $304(56.7)$ & $<0.001$ \\
\hline Surgical approach, $\mathrm{n}(\%)$ & 910 & & & \\
\hline Any anterior & & $85(21.5)$ & $117(22.8)$ & \multirow{3}{*}{0.52} \\
\hline Any posterior & & $297(75.0)$ & $372(72.4)$ & \\
\hline Any anterior \& posterior & & $14(3.5)$ & $25(4.9)$ & \\
\hline$\geq 3$ motion segments treated, $n(\%)$ & 910 & $58(14.6)$ & $130(25.3)$ & $<0.001$ \\
\hline Fusion surgery, $\mathrm{n}(\%)$ & 910 & $189(47.7)$ & $357(69.5)$ & $<0.001$ \\
\hline Minimally invasive surgery, $\mathrm{n}(\%)$ & 910 & $90(22.7)$ & $132(25.7)$ & 0.30 \\
\hline Revision surgery, $\mathrm{n}(\%)$ & 910 & $47(11.9)$ & $84(16.3)$ & 0.057 \\
\hline Grade $\geq 3$ osteotomy, ${ }^{25} \mathrm{n}(\%) \ddagger$ & 910 & $14(3.5)$ & $21(4.1)$ & 0.67 \\
\hline
\end{tabular}

Boldface type indicates statistical significance.

* Good pain control is defined as an NRS score $\leq 4$, and poor pain control is defined as an NRS score $>4$.

$†$ Neck Disability Index $\geq 50$ and Oswestry Disability Index $>40$.

$\ddagger$ At least pedicle or partial body resection. 
TABLE 3. Clinical score assigned to each predictor for poor postoperative pain control (NRS score for pain at rest $>4$ ) after elective spine surgery

\begin{tabular}{lcrc}
\hline \multicolumn{1}{c}{ Predictor } & $\mathrm{aOR}(95 \% \mathrm{Cl})$ & $\mathrm{p}$ Value & Score \\
\hline Age $<70$ yrs & $1.69(1.20-2.37)$ & $\mathbf{0 . 0 0 2}$ & 2 \\
\hline Female sex & $1.73(1.29-2.30)$ & $<0.001$ & 2 \\
\hline Daily preop opioid use & $2.72(1.93-3.85)$ & $<0.001$ & 3 \\
\hline Preop NRS neck/back pain $>7$ & $1.45(1.07-1.98)$ & $\mathbf{0 . 0 1 8}$ & 1 \\
\hline $\begin{array}{l}\text { Moderate to severe depression } \\
\text { (PHQ-9 } \geq 10)\end{array}$ & $1.39(1.02-1.91)$ & $\mathbf{0 . 0 3 8}$ & 1 \\
\hline$\geq 3$ motion segments treated & $2.01(1.38-2.93)$ & $<0.001$ & 2 \\
\hline Fusion surgery & $2.12(1.57-2.88)$ & $<0.001$ & 2 \\
\hline Total score & & & $0-13$ \\
\hline
\end{tabular}

Boldface type indicates statistical significance.

stantiated ${ }^{27}$ In fact, numerous practice guidelines recommend against the initiation of long-term opioids for noncancer chronic pain. ${ }^{28,29}$ Preoperative opioid use has previously been associated with poorer standardized outcome scale scores after spine surgery, including the 12-Item Short Form Health Survey, Oswestry Disability Index, and Neck Disability Index at the 12-month follow-up. ${ }^{30}$ In this study, $96.4 \%$ of patients who were consuming daily opioids had been taking them for more than 3 months. This points to an opportunity to reduce opioid prescribing in the preoperative setting. Such preoperative opioid tapering has been shown to improve patient-reported outcomes following total joint arthroplasty ${ }^{31,32}$ and to improve depression and anxiety, both of which are associated with worse pain postoperatively. ${ }^{9,30,33}$

Increasing scores on the PHQ-9 (evaluating depression) and preoperative axial neck or back pain were other modifiable risk factors identified in this study. Depression has been previously associated with inadequately controlled postoperative pain ${ }^{9}$ and poor surgical outcomes across surgical disciplines. ${ }^{34,35}$ Similarly, preoperative pain was also shown to be predictive of increased postoperative pain in other disciplines. ${ }^{9}$ It has been proposed that current pain intensity, expectations of pain, and memory of pain all have a significant influence on the severity of future pain. ${ }^{36}$ Both preoperative depression and pain intensity may be significantly improved by psychotherapy methods such as acceptance and commitment therapy. ${ }^{37}$ Acceptance and commitment therapy have also been shown to be effective in improving a myriad of other mental health disorders, such as anxiety, pain catastrophizing, and addictions. ${ }^{38,39}$

Nonmodifiable risk factors that were associated with poor pain control included younger age, female sex, surgery involving $\geq 3$ motion segments, and fusion. Both younger age and female sex have been previously associated with increased postoperative pain and higher analgesic requirements in other disciplines. ${ }^{9,40}$ Surgeries involving more motion segments and fusion surgeries usually require larger incisions and more soft-tissue manipulation, leading to increased postoperative pain. However, interestingly, minimally invasive surgery was not significantly associated with pain control status in this study. This is
TABLE 4. SSLRs and predicted probability for poor postoperative pain control for each tier of the CAPPS score

\begin{tabular}{lcc}
\hline CAPPS Score & $\begin{array}{c}\text { SSLR } \\
(95 \% \mathrm{Cl})\end{array}$ & $\begin{array}{c}\text { Predicted Probability of } \\
\text { Poor Pain Control, \%* }\end{array}$ \\
\hline Eight-tier & & \\
\hline $0-2$ & $0.25(0.16-0.37)$ & 24.2 \\
\hline 3 & $0.46(0.26-0.81)$ & 37.6 \\
\hline 4 & $0.46(0.33-0.64)$ & 37.3 \\
\hline 5 & $1.23(0.79-1.91)$ & 61.5 \\
\hline 6 & $1.08(0.76-1.53)$ & 58.4 \\
\hline 7 & $1.44(0.99-2.09)$ & 65.1 \\
\hline 8 & $1.77(1.09-2.89)$ & 69.7 \\
\hline $9-13$ & $4.40(2.90-6.67)$ & 85.1 \\
\hline Three-tier & & \\
\hline Low risk (0-4) & $0.36(0.30-0.45)$ & 32.0 \\
\hline High risk (5-8) & $1.32(1.12-1.55)$ & 63.0 \\
\hline Extreme risk (9-13) & $4.40(2.90-6.67)$ & 85.1 \\
\hline
\end{tabular}

Pretest probability of outcome used for calculation: $56.5 \%$.

${ }^{*}$ NRS score $>4$

contradictory to numerous reports that have suggested that minimally invasive surgery has improved pain outcomes when compared with open surgery. ${ }^{41}$ In this study, a procedure was considered minimally invasive if soft-tissue dilation rather than stripping dissection was performed. It is possible that a positive effect on pain was not seen because, for smaller procedures at least, more patients may be discharged within 24 hours when minimally invasive techniques are used.

Strategies to reduce acute postoperative pain are a large part of Enhanced Recovery After Surgery programs ${ }^{42}$ The ability of clinicians to risk-stratify patients preoperatively (using the CAPPS score developed in this study) creates an opportunity to develop anticipatory therapies and personalized clinical care pathways. For example, patients identified as extreme risk may be better candidates for resource-intensive therapies such as preoperative opioid deprescribing programs and acceptance and commitment therapy. ${ }^{31,37}$ On the other hand, less-resource-intense therapies may be appropriate for patients identified as high risk, for example, the use of preemptive analgesia and intraoperative intrathecal morphine injection following lumbar surgery. ${ }^{6,12}$ The CAPPS score and the predictors identified in this study can also be used to inform patient selection and appropriate adjustment of confounders in future pain studies in spine surgery. In terms of knowledge translation, the probability of poor pain control informed through this study can help frame patient education, inform expected pain after surgery, and improve shared decision-making regarding personalized preoperative and perioperative treatment strategies to improve pain outcomes. Notably, inadequate preoperative patient education is correlated with higher postoperative pain and increased length of hospital stay. ${ }^{43,44}$ Individualized and preventative approaches to postoperative pain management may lead to a reduction in postoperative opioid utilization, recovery time, and healthcare costs and improved patient satisfaction. 

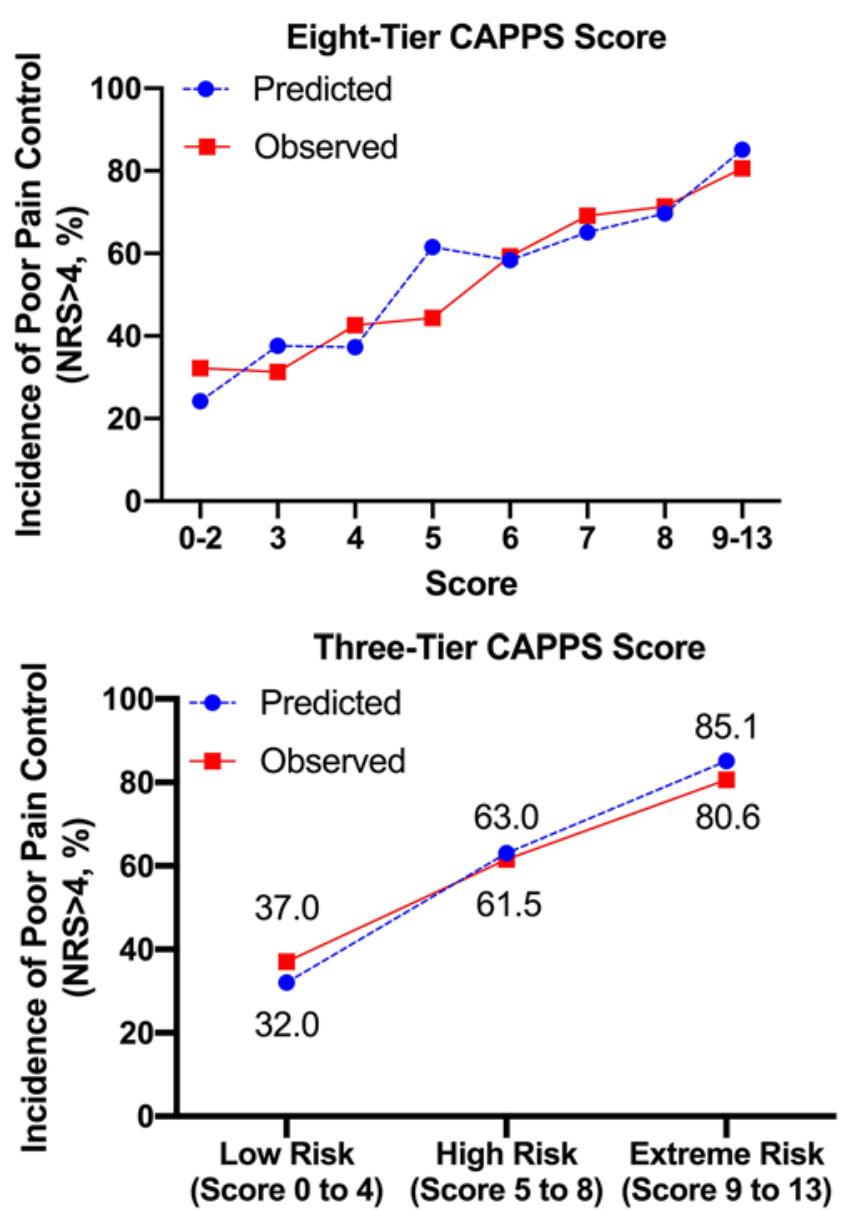

FIG. 2. CAPPS score. Predicted probability versus observed incidence of poor pain control (NRS score for pain $>4$ ) after elective spine surgery in the validation cohort $(n=310)$. Probabilities across the eight-tier CAPPS score (upper) and three-tier CAPPS score (lower). Figure is available in color online only.

\section{Limitations}

Pain is a subjective experience, with psychological, biological, and environmental determinants all contributing to the unpleasant experience. As such, developing a prediction rule that captures all elements that predict pain is inherently difficult. Factors such as anxiety, pain catastrophizing, and kinesiophobia have been associated with poorly controlled postoperative pain and were not evaluated in this study. ${ }^{9,45}$ Future studies should evaluate whether these factors are important in spine surgery and update the CAPPS score accordingly. Sampling bias during patient recruitment could not be assessed because data for patients not consenting to the CSORN registry were not available. The score developed here includes variables that are easily acquired in the preoperative setting. One variable, PHQ-9, may not be routinely gathered and may be a deterrent to adoption of this score in clinical practice. However, it is our hope that more spine clinics will adopt the practice of routine preoperative evaluation of depression in a quantitative manner. Our score exhibited a percentage misclassification between low- and high- or extreme-risk groups of $38.0 \%$ and $29.9 \%$, respectively. Thus, approximately one-third of patients were misclassified as expecting poor pain control when in fact they had good control, and vice versa. This may lead to inappropriate overuse or underuse of pain-mitigating treatment strategies, leading to wasted healthcare resources or subjecting some patients to unnecessary risk but still improvement from the status quo. Some of the variables examined (e.g., grade 3 osteotomy or more, and anterior-posterior surgery) had small sample sizes. Type 2 error may have limited our ability to attribute predictive value to these variables in this study. Lastly, the score developed in this study was not externally validated. Future studies demonstrating adequate predictive performance in an external population should be performed before widespread adoption of this prediction rule.

\section{Conclusions}

Inadequate pain control is common following spine surgery. The internally validated CAPPS score, based on 7 easily acquired characteristics identified in this study, accurately predicted the incidence of poorly controlled pain after spine surgery. This score can be used to facilitate preoperative patient education and the development of personalized clinical care pathways to improve postoperative acute pain outcomes.

\section{Acknowledgments}

M.M.H.Y. has received funding from the Clinical Investigator Program, University of Calgary and the Canadian Institute of Health Research. N.J. receives grant funding paid to her institution for grants unrelated to this work from NINDS (NIH U24NS107201, NIH IU54NS100064) and PCORI.

\section{References}

1. Patil PG, Turner DA, Pietrobon R. National trends in surgical procedures for degenerative cervical spine disease: 19902000. Neurosurgery. 2005;57(4):753-758.

2. Weinstein JN, Lurie JD, Olson PR, et al. United States' trends and regional variations in lumbar spine surgery: 1992-2003. Spine (Phila Pa 1976). 2006;31(23):2707-2714.

3. Gerbershagen HJ, Pogatzki-Zahn E, Aduckathil S, et al. Procedure-specific risk factor analysis for the development of severe postoperative pain. Anesthesiology. 2014;120(5): 1237-1245.

4. Katz J, Jackson M, Kavanagh BP, Sandler AN. Acute pain after thoracic surgery predicts long-term post-thoracotomy pain. Clin J Pain. 1996;12(1):50-55.

5. Apfelbaum JL, Chen C, Mehta SS, Gan TJ. Postoperative pain experience: results from a national survey suggest postoperative pain continues to be undermanaged. Anesth Analg. 2003;97(2):534-540.

6. Chou R, Gordon DB, de Leon-Casasola OA, et al. Management of postoperative pain: a clinical practice guideline from the American Pain Society, the American Society of Regional Anesthesia and Pain Medicine, and the American Society of Anesthesiologists' Committee on Regional Anesthesia, Executive Committee, and Administrative Council. J Pain. 2016;17(2):131-157.

7. Sekar C, Rajasekaran S, Kannan R, et al. Preemptive analgesia for postoperative pain relief in lumbosacral spine surgeries: a randomized controlled trial. Spine J. 2004;4(3):261-264.

8. Sommer M, de Rijke JM, van Kleef M, et al. The prevalence of postoperative pain in a sample of 1490 surgical inpatients. Eur J Anaesthesiol. 2008;25(4):267-274. 
9. Yang MMH, Hartley RL, Leung AA, et al. Preoperative predictors of poor acute postoperative pain control: a systematic review and meta-analysis. BMJ Open. 2019;9(4):e025091.

10. Moons KG, Altman DG, Reitsma JB, et al. Transparent Reporting of a multivariable prediction model for Individual Prognosis Or Diagnosis (TRIPOD): explanation and elaboration. Ann Intern Med. 2015;162(1):W1-W73.

11. Canadian Spine Outcomes and Research Network (CSORN). Canadian Spine Society. Accessed July 17, 2020. http:// spinecanada.ca/professional-resources/csorn/

12. Dhaliwal P, Yavin D, Whittaker T, et al. Intrathecal morphine following lumbar fusion: a randomized, placebo-controlled trial. Neurosurgery. 2019;85(2):189-198.

13. Guay J, Suresh S, Kopp S, Johnson RL. Postoperative epidural analgesia versus systemic analgesia for thoraco-lumbar spine surgery in children. Cochrane Database Syst Rev. 2019;1(1):CD012819.

14. Gerbershagen HJ, Rothaug J, Kalkman CJ, Meissner W. Determination of moderate-to-severe postoperative pain on the numeric rating scale: a cut-off point analysis applying four different methods. Br J Anaesth. 2011;107(4):619-626.

15. Breivik H, Borchgrevink PC, Allen SM, et al. Assessment of pain. Br J Anaesth. 2008;101(1):17-24.

16. Henderson IC, Patek AJ. The relationship between prognostic and predictive factors in the management of breast cancer. Breast Cancer Res Treat. 1998;52(1-3):261-288.

17. Gasparini G, Pozza F, Harris AL. Evaluating the potential usefulness of new prognostic and predictive indicators in node-negative breast cancer patients. J Natl Cancer Inst. 1993;85(15):1206-1219.

18. Peduzzi P, Concato J, Kemper E, et al. A simulation study of the number of events per variable in logistic regression analysis. J Clin Epidemiol. 1996;49(12):1373-1379.

19. Akinwande MO, Dikko HG, Samson A. Variance inflation factor: as a condition for the inclusion of suppressor variable(s) in regression analysis. Open J Stat. 2015;5(7): 754-767.

20. Tu JV, Naylor CD. Clinical prediction rules. J Clin Epidemiol. 1997;50(6):743-744.

21. Peirce JC, Cornell RG. Integrating stratum-specific likelihood ratios with the analysis of ROC curves. Med Decis Making. 1993;13(2):141-151.

22. Fagan TJ. Letter: Nomogram for Bayes theorem. $N$ Engl J Med. 1975;293(5):257.

23. Steyerberg EW, Vergouwe Y. Towards better clinical prediction models: seven steps for development and an ABCD for validation. Eur Heart J. 2014;35(29):1925-1931.

24. Shaikh S. Measures derived from a 2 × 2 table for an accuracy of a diagnostic test. J Biomet Biostat. 2011;2(5):1-4.

25. Schwab F, Blondel B, Chay E, et al. The comprehensive anatomical spinal osteotomy classification. Neurosurgery. 2014; 74(1):112-120.

26. Kampe $\mathrm{S}$, Wendland $\mathrm{M}$, Welter $\mathrm{S}$, et al. Independent predictors for higher postoperative pain intensity during recovery after open thoracic surgery: a retrospective analysis in 621 patients. Pain Med. 2018;19(8):1667-1673.

27. Busse JW, Craigie S, Juurlink DN, et al. Guideline for opioid therapy and chronic noncancer pain. CMAJ. 2017;189(18): E659-E666.

28. Bernstein IA, Malik Q, Carville S, Ward S. Low back pain and sciatica: summary of NICE guidance. BMJ. 2017;356: i6748.

29. Sall J, Rodgers E. VA/DoD clinical practice guideline for opioid therapy for chronic pain. Abstract. J Am Psychiatr Nurses Assoc. 2018;24(4):378.

30. Lee D, Armaghani S, Archer KR, et al. Preoperative opioid use as a predictor of adverse postoperative self-reported outcomes in patients undergoing spine surgery. J Bone Joint Surg Am. 2014;96(11):e89.
31. Nguyen L-CL, Sing DC, Bozic KJ. Preoperative reduction of opioid use before total joint arthroplasty. J Arthroplasty. 2016;31(9)(suppl):282-287.

32. Hassamal S, Haglund M, Wittnebel K, Danovitch I. A preoperative interdisciplinary biopsychosocial opioid reduction program in patients on chronic opioid analgesia prior to spine surgery: a preliminary report and case series. Scand J Pain. 2016;13:27-31.

33. Armaghani SJ, Lee DS, Bible JE, et al. Preoperative narcotic use and its relation to depression and anxiety in patients undergoing spine surgery. Spine (Phila Pa 1976). 2013;38(25): 2196-2200.

34. Sinikallio S, Aalto T, Airaksinen O, et al. Depression is associated with a poorer outcome of lumbar spinal stenosis surgery: a two-year prospective follow-up study. Spine (Phila Pa 1976). 2011;36(8):677-682.

35. Caumo W, Schmidt AP, Schneider CN, et al. Preoperative predictors of moderate to intense acute postoperative pain in patients undergoing abdominal surgery. Acta Anaesthesiol Scand. 2002;46(10):1265-1271.

36. Kalso E. Memory for pain. Acta Anaesthesiol Scand Suppl. 1997;110(S110):129-130.

37. Abid Azam M, Weinrib AZ, Montbriand J, et al. Acceptance and Commitment Therapy to manage pain and opioid use after major surgery: preliminary outcomes from the Toronto General Hospital Transitional Pain Service. Can J Pain. 2017:1(1):37-49.

38. A-Tjak JG, Davis ML, Morina N, et al. A meta-analysis of the efficacy of acceptance and commitment therapy for clinically relevant mental and physical health problems. Psychother Psychosom. 2015;84(1):30-36.

39. Trompetter HR, Bohlmeijer ET, Fox J-P, Schreurs KM. Psychological flexibility and catastrophizing as associated change mechanisms during online Acceptance \& Commitment Therapy for chronic pain. Behav Res Ther. 2015;74: $50-59$.

40. Aubrun F, Salvi N, Coriat P, Riou B. Sex- and age-related differences in morphine requirements for postoperative pain relief. Anesthesiology. 2005;103(1):156-160.

41. Phan K, Rao PJ, Kam AC, Mobbs RJ. Minimally invasive versus open transforaminal lumbar interbody fusion for treatment of degenerative lumbar disease: systematic review and meta-analysis. Eur Spine J. 2015;24(5):1017-1030.

42. Elsarrag M, Soldozy S, Patel P, et al. Enhanced recovery after spine surgery: a systematic review. Neurosurg Focus. 2019; 46(4):E3.

43. Aarts M-A, Okrainec A, Glicksman A, et al. Adoption of enhanced recovery after surgery (ERAS) strategies for colorectal surgery at academic teaching hospitals and impact on total length of hospital stay. Surg Endosc. 2012;26(2): $442-450$.

44. Stomberg MW, Wickström K, Joelsson H, et al. Postoperative pain management on surgical wards-do quality assurance strategies result in long-term effects on staff member attitudes and clinical outcomes? Pain Manag Nurs. 2003;4(1): $11-22$.

45. Khan RS, Ahmed K, Blakeway E, et al. Catastrophizing: a predictive factor for postoperative pain. Am J Surg. 2011; 201(1):122-131.

\section{Disclosures}

Dr. Jetté: honorarium for work as an associate editor of Epilepsia. Dr. Lewkonia: honoraria from AO Spine North America and travel costs from Medtronic Canada. Dr. Jacobs: consultant for Medtronic, Stryker, and DePuy Synthes.

\section{Author Contributions}

Conception and design: Casha, Yang, Riva-Cambrin, Jetté, Sajobi. 
Acquisition of data: Casha, Yang, Cunningham, Soroceanu, Lewkonia, Jacobs. Analysis and interpretation of data: Casha, Yang, Riva-Cambrin, Jetté, Sajobi. Drafting the article: Yang. Critically revising the article: all authors. Reviewed submitted version of manuscript: all authors. Approved the final version of the manuscript on behalf of all authors: Casha. Statistical analysis: Yang. Study supervision: Casha, Riva-Cambrin, Jetté, Sajobi.

\section{Supplemental Information}

\section{Online-Only Content}

Supplemental material is available with the online version of the article.

eFigure and eTables. https://thejns.org/doi/suppl/10.3171/ 2020.5.SPINE20347.

\section{Previous Presentations}

Portions of this work were presented orally at the CNS 2019 Annual Meeting, San Francisco, California, October 23, 2019, and at the 36th Annual Meeting of the Section on Disorders of the Spine and Peripheral Nerves, Las Vegas, Nevada, March 6, 2020, where it was awarded the Charles Kuntz Scholar Award.

\section{Correspondence}

Steven Casha: University of Calgary, AB, Canada. scasha@ ucalgary.ca. 